NBER WORKING PAPER SERIES

\title{
WHY ARE PROFESSORS "POORLY PAID"?
}

\author{
Daniel S. Hamermesh \\ Working Paper 24215 \\ http://www.nber.org/papers/w24215
NATIONAL BUREAU OF ECONOMIC RESEARCH
1050 Massachusetts Avenue
Cambridge, MA 02138
January 2018

I thank Jeff Biddle, Ronald Ehrenberg, Richard Murphy and Stephen Trejo for helpful suggestions, and all the IZA Research Fellows and Affiliates who responded to the survey discussed in Section III. The views expressed herein are those of the author and do not necessarily reflect the views of the National Bureau of Economic Research.

The author has disclosed a financial relationship of potential relevance for this research. Further information is available online at http://www.nber.org/papers/w24215.ack

NBER working papers are circulated for discussion and comment purposes. They have not been peer-reviewed or been subject to the review by the NBER Board of Directors that accompanies official NBER publications.

(C) 2018 by Daniel S. Hamermesh. All rights reserved. Short sections of text, not to exceed two paragraphs, may be quoted without explicit permission provided that full credit, including (C) notice, is given to the source. 
Why Are Professors "Poorly Paid"?

Daniel S. Hamermesh

NBER Working Paper No. 24215

January 2018

JEL No. J31,J33,J44

\section{ABSTRACT}

Using Current Population Survey data, I demonstrate a 15-percentage point wage disadvantage among academics compared to all other doctorate-holders with the same demographics. Timediary data show that academics' work hours are distributed more evenly over the week and day, although their total workweeks are equally long. This smoother distribution of work time accounts for as much as one-third of the wage disadvantage. Survey data (of economists only) indicate that flexible scheduling is an attraction, but only fourth among the characteristics of academic life.

Daniel S. Hamermesh

Department of Economics

Barnard College

3009 Broadway

New York, NY 10027

and NBER

hamermes@eco.utexas.edu 


\section{Introduction}

An immense ongoing literature extending back at least to the early 1970s has provided econometric evidence on the determinants of salaries of economists (Johnson and Stafford, 1974a; Hilmer et al., 2015). ${ }^{1}$ The econometric literature on salary determination more generally in academe is also extensive and continuing, with substantial concentration on differences by gender (Johnson and Stafford, 1974b; McDonald and Sorensen, 2017). Far less research has provided evidence on how earnings of university faculty differ from earnings in other professions and from workers generally. A few comparisons of averages exist (AAUP, 2002, Figure 4; AAUP, 2006, Figure 3), and a comparison of long-term trends in relative earnings (in Germany) is available (Sohn, 2016).

Apparently missing from this literature is a detailed comparison of how earnings of university instructors differ from otherwise identical workers who have spent the same amount of time in formal schooling, which is the relevant measure of the purely pecuniary advantage/disadvantage of being in academe. Even more important, there is no econometric evidence exploring the underlying causes of any (adjusted) earnings differential between academics and other highly-educated workers. Here I use a variety of data sets, including two publicly-available nationally representative American surveys and an online survey of academic economists that I conducted, to shed light on these issues.

\section{Are They Really Paid Poorly?}

To examine these pay differentials, I first use the Current Population Survey-Merged Outgoing Rotation Groups (CPS-MORG) for 2012-16, restricting the sample to those respondents

\footnotetext{
${ }^{1}$ Bok (1993) is a good general discussion of the compensation of academics and other highly-educated professionals.
} 
who indicated that they had an advanced professional degree, such as a J.D., M.D., other similar degree or a Ph.D. or Ed.D. (referred to hereafter as doctorate-holders or advanced-degree-holders). Other restrictions required that the respondent be at least age 25, earn at least $\$ 200$ per week and report usually working some positive number of hours. A Ph.D. or Ed.D.-holder who indicated an occupation of "postsecondary teacher" was coded as an academic; the other doctorate-holders included in the sample were not. ${ }^{2}$ Top-coded earnings were replaced, as is standard, by 1.5 times the top-coded amount. Because the earnings of 21 percent of non-academics and 9 percent of academics were top-coded, differences at quantiles up through the $75^{\text {th }}$ percentile are more reliable than evidence on means, so that I rely more on statistics and estimation at quantiles.

The upper panel of Table 1 presents statistics describing the earnings of these advanceddegree-holders. Comparing pay differences at various quantiles of the distributions, there is essentially no difference in pay at the lowest decile; but the differences rise steadily as we move up the earnings distribution. At the means academics receive 18 percent lower pay than nonacademic advanced degree-holders; at the medians, the difference is "only" 12 percent. Although on average professors appear poorly paid compared to other highly-educated workers, their average weekly earnings are 44 percent higher than those of workers without advanced degrees (who are of the same age and have a workweek of the same length).

These raw differences in earnings might be generated by differences between the two groups in the workers' characteristics. To examine this possibility in a regression context I relate the logarithm of earnings to an indicator of being in academe or not, including as control variables

\footnotetext{
${ }^{2}$ The education categories included are those for which the variable grade92 in the CPS-MORG equals 45 or 46 . The occupation code for academics is 2200 , "postsecondary teachers."
} 
a large number of the respondents' demographic and economic characteristics. ${ }^{3}$ The least-squares estimate of the adjusted pay difference between professors and other advanced-degree-holders shows a disadvantage of about 13 percent. Quantile estimates of the same equation yield essentially the same conclusions as the comparison of averages: At the $10^{\text {th }}$ percentile there is no (adjusted) pay difference; at the median the pay disadvantage is about 15 percent; and it rises steadily moving up the pay distribution. Professors are "poorly paid" compared to others with the same educational attainment and many other demographic characteristics.

One might be concerned that the comparison group is not sufficiently exclusive, that the choices people make to enter postsecondary teaching are made during their time as doctoral students, not when, for example, choosing to seek a Ph.D. rather than a J.D. If we restrict the comparison group only to those people who have received a doctorate, not another advanced professional degree such as a J.D. or M.D., the results look very similar to those shown in Table 1. In the least-squares earnings regression the estimated parameter on the indicator for postsecondary teachers rises slightly, to -0.135 ; at the quantiles the estimates change only slightly, becoming $-0.004,-0.080,-0.144$ and -0.224 at the $10^{\text {th }}, 25^{\text {th }}, 50^{\text {th }}$ and $75^{\text {th }}$ percentiles respectively.

\section{What Causes the Pay Disadvantage?}

The American Time Use Survey (ATUS), 2003-2015, provides enough observations on academics and other doctorate-holders to draw reliable inferences about how differences in work time and timing might account for some of the pay disadvantage in academe. The ATUS takes a sub-sample of people who were recent CPS respondents and asks them to complete diaries cataloging their activities on the previous day (Hamermesh et al., 2005). Using the same restrictions as in Section II to create a sub-sample of doctorate-holders yields nearly $500 \mathrm{Ph}$.D. or

\footnotetext{
${ }^{3}$ These are quadratics in usual weekly hours and age, indicators of gender and marital status, number of own children under age 18 and vectors of indicators of metropolitan status, survey year and state of residence.
} 
Ed.D.-holders in university teaching and nearly 2,800 other advanced-degree-holders. Table 2 presents various statistics describing their work time.

As seen in the top row of the table, recalled usual weekly hours (the standard CPS measure, which is also included in the ATUS) are slightly higher among academics. The second row presents calculations based on work time reported in the time diaries, calculated by averaging over days to obtain the implied work hours in a representative week. ${ }^{4}$ While for both groups the weekly hours implied by the time diaries are below recalled usual hours, the drop is much larger among academics, with the result that diary workhours are more nearly equal between the two groups than are their recalled hours. The excess of recalled over diary hours is specific to these high-earners: Among less-educated adult workers the two measures are nearly identical. ${ }^{5}$

While average hours are demonstrably the same in the two groups, their temporal distributions differ significantly. As the third and fourth rows of Table 2 show, professors do much more of their work on weekends than do other advanced-degree-holders, and they do less during weekdays. They put in nearly 50 percent more worktime on weekends than other highly-educated workers (and 50 percent more than less-educated workers too). Professors spread their work effort more evenly over the week than other advanced-degree-holders.

They also spread their work more evenly over the day. The fifth row of Tale 2 lists the percentage of days on which members of the two groups are working and performing part of their work in the evening (at some time between 7:01PM and 10PM). The sixth row presents the same

\footnotetext{
${ }^{4}$ The 46 hours are well below the work time reported in the large national sample of professors used by Allgood and Walstad (2013). The difference might result from differences in the survey questions or perhaps from that survey's basis in very long recall.

${ }^{5}$ The difference between recalled and diary work time here and its absence among less educated workers implicitly supports the idea that there is non-classical measurement error in recalled usual weekly hours that is positively correlated with hourly pay (Barrett and Hamermesh, 2018).
} 
calculations, but for work performed at night (at some time between 10:01PM and 6AM). Both comparisons show that academics are significantly more likely than holders of other doctorates to be working in the evening or at night, to be spreading their work more over the day.

Unsurprisingly too, professors' time allocations across the year also differ from those of other highly-educated workers. For professors and other doctorate-holders the final pair of rows in Table 2 presents calculations of the average workweek during the American academic summer months (June-August) and during the other nine months. ${ }^{6}$ Professors' work is more variable seasonally, which, unlike the weekly and daily variation in work timing, implies less temporal smoothing of leisure, which may seem undesirable. But summer breaks might actually be desirable, as they enable academics to spend more time with their families (which might be especially attractive if the academic has school-age children who have school vacations in summer). ${ }^{7}$

Ignoring the seasonal and daily differences, we can examine how much the weekly smoothing of leisure might contribute to utility, and thus how much of the wage disadvantage in academe might reflect a compensating differential for the greater equality of leisure time across days of the week. Consider the CES utility function defined over weekdays and weekend days:

(1) $\mathrm{U}=5\left[\delta \mathrm{X}_{\mathrm{d}}^{\rho}+(1-\delta) \mathrm{L}_{d}^{\rho}\right]^{1 / \rho}+2\left[\delta \mathrm{Xe}_{\mathrm{e}}^{\rho}+(1-\delta) \mathrm{L}_{\mathrm{e}}^{\rho}\right]^{1 / \rho}$,

where $\mathrm{X}$ is goods expenditure, $\mathrm{L}$ is non-market time (assumed to be 16 - daily work hours), the subscripts $d$ and e denote weekdays and weekend days respectively, and $\sigma=1 /(1-\rho)$ is the elasticity of substitution between goods and time. I assume that weekly utility is additive in utility across

\footnotetext{
${ }^{6}$ That the weighted average of the weekday and weekend hours departs from the weekly average arises from the sample weighting. The average of the raw weekend and weekday averages of course equals the weekly average.

${ }^{7}$ Re-calculating all the statistics in Table 2 using only those ATUS respondents with doctorates rather than both doctorates and professional degrees as the comparison group changes the comparisons only minutely.
} 
the days and that each day is weighted equally. Clearly this measures only the extent of the compensating differential for the worker at the margin of choice between the two occupations, academe and other. Those academics with inframarginal preferences for the characteristics of academic life are earning rents given the market wage differential.

The simulation exercise bases the measures of average daily non-work time on weekdays and weekend days for professors and other doctorate-holders using the estimates from the ATUS sub-sample that are presented in Table 2. It then asks: Given others' weekly earnings, what earnings disadvantage would give the same utility to a professor at the margin of choice between the two occupations (under the assumption that all earnings are spent and are consumed equally across days)?

For various combinations of $\delta$ and $\sigma$, ranging from nearly fixed-proportions to quite easy substitution of goods and leisure, Table 3 lists the percentage shortfall in professors' earnings that would equalize utility in (1) given the observed day-to-day distributions of work hours in the two occupations. When substitution is quite difficult, the spreading of professors' work time across the week can account for nearly five percentage points of the wage differential, i.e., almost one-third of the earnings difference at the median shown in Table 1. With higher values of $\sigma$-easier goodstime substitution - the compensating differential is smaller; but only if substitution is very easy-$\sigma \geq 0.75$ - does the difference in work timing account for less than 10 percent of the observed differential. Under what seem like reasonable assumptions about utility a not tiny, but also not huge part of the wage differential can be explained by the more equal distribution of leisure across days of the week that is observed among academics.

No doubt other, more complicated utility functions, perhaps including temporal variety as an argument, might rationalize more of the earnings differential, since temporal variety is a 
superior activity (Hamermesh. 2005). These might include the reduced work hours in summers or the within-day flexibility demonstrated in Table 2. All of these differences might be classified as allowing flexibility in scheduling/time use, which might make this occupation more attractive than others requiring the same educational attainment. But do academics care about this flexibility?

To examine this question, I emailed a very short open-ended survey (shown in the Appendix) to nearly 1000 academics located around the world who specialize in the study of labor markets. ${ }^{8}$ Completed usable responses were received from 289 of them. Those surveyed were asked to list their gender and the year when their teaching career began, and also to describe the three aspects of their job as university instructor that made it most attractive to them. ${ }^{9}$ I coded these free-form responses into six categories: Freedom and novelty of research; teaching/dealing with students, undergraduate and/or graduate; intellectual and social interactions with colleagues; scheduling freedom (any mention of flexible time); impact on policy or the public; and miscellaneous (including being one’s own boss, travel, and others).

Based on probits describing the probability of listing each characteristic as one's top-three attraction to academe, and using as explanatory variables location in North America, gender and years of teaching experience, Figure 1 shows the predicted probabilities (in percentages) that someone located in North America listed the attraction. Freedom and novelty of research, and the satisfaction of working with young minds, are by far the most important attractions into academe. Only 41 percent of respondents listed time flexibility as a top-three attraction, slightly fewer than listed enjoying intellectual and social interactions with colleagues.

\footnotetext{
${ }^{8}$ Surveys attempting to infer sources of academics' job satisfaction are ubiquitous (e.g., Hagedorn, 2000).

${ }^{9}$ Their location, North America versus elsewhere, was inferred from their email addresses.
} 
Table 4 presents the results of the probit estimation of the describing each job characteristic as a function of the three variables on which demographic information was collected. Female academics are more interested than men in flexible scheduling, but not significantly so. The other two personal characteristics on which the survey obtained information, however, have significant impacts on the probability of listing "flexible scheduling" as a top-three desired characteristic of an academic job. More experienced academics are less likely to mention this aspect of academic life. North American faculty are more likely to do so, perhaps because the characteristics of work timing in this occupation in North America, especially in the U.S., are more different from those of non-academic work compared to the differences in the rest of the world. ${ }^{10}$ With the description "flexible scheduling” covering much more than merely flexibility across days, the inability of the simulations whose results are presented in Table 3 to attribute more than one-third of the earnings shortfall of academics to their more even day-to-day distribution of work time is not surprising.

\section{Conclusion}

I have documented a fairly large wage disadvantage of academics behind otherwise identical advanced-degree-holders. Part of the disadvantage arises from the more equal distribution of work time across days of the week among academics; but in a simple model of utility this difference alone can account for no more than one-third of the earnings differential. This small proportion is not surprising: The expressed preferences of academics suggest that the advantages of work timing in academe are far from its most important attraction to them.

The unexplained part of the pay disadvantage in academe might be accounted for by selfselection arising from differences in preferences of those who choose this sector compared to

\footnotetext{
${ }^{10}$ Consistent with this implicit double-difference, North-American academics are significantly less likely than others to list having an impact on policy as an attraction, perhaps because the size of the U.S. makes having such an impact more difficult than elsewhere.
} 
others (as in Goddeeris, 1988, examining attorneys' choices, and Stern, 2004, examining biologists’ choices). It may also result, even if workers’ preferences for work characteristics are homogeneous, from the greater importance of other aspects of the academic life unrelated to work timing. That respondents to the survey of economists noted that such things as independence and interactions with new ideas and with students are more important to them than flexibility of time use suggests that this might be the case. Indeed, isolating the role of independence from being supervised by others in determining compensation would be a useful avenue for future study of the academic labor market and indeed of professional occupations more generally. 


\section{References}

Sam Allgood and William Walstad, "How Economists Allocate Time to Teaching and Research,” American Economic Association, Papers and Proceedings, 103 (May 2013): 654-8.

American Association of University Professors (AAUP), “Annual Report on the Economic Status of the Profession,” Academe (March-April 2002, 2006).

Garry Barrett and Daniel Hamermesh, "Labor Supply Elasticities: Overcoming Nonclassical Measurement Error Using More Accurate Hours Data,” Journal of Human Resources, 2018, forthcoming.

Derek Bok, The Cost of Talent. New York: Free Press, 1993.

John Goddeeris, “Compensating Differentials and Self-Selection: An Application to Lawyers,” Journal of Political Economy, 96 (April 1988): 411-28.

Linda S. Hagedorn, “Conceptualizing Faculty Satisfaction,” New Directions for Institutional Research, 100 (Spring 2000): 5-20.

Daniel Hamermesh, “Routine,” European Economic Review, 49 (Jan.2005): 29-53.

--------------------, Harley Frazis and Jay Stewart, "Data Watch: The American Time Use Survey,” Journal of Economic Perspectives, 19 (Winter 2005): 221-32.

Michael Hilmer, Michael Ransom and Christina Hilmer, "Fame and the Fortune of Academic Economists: How the Market Rewards Influential Research in Economics,” Southern Economic Journal, 82 (Oct. 2015): 430-52.

George Johnson and Frank Stafford, "Lifetime Earnings in a Professional Labor Market: Academic Economists,” Journal of Political Economy, 82 (May-June 1974): 549-69, a.

and -------------------, “The Earnings and Promotion of Women Faculty,” American Economic Review, 64 (Dec. 1974): 888-903, b.

James McDonald and Jeff Sorensen, “Academic Salary Compression across Disciplines and over Time,” Economics of Education Review, 59 (Aug. 2017): 87-104.

Alexander Sohn, "Poor University Professors? The Relative Earnings Decline of German Professors During the Twentieth Century," Scandinavian Economic History Review, 64 (2016): 84-102.

Scott Stern, “Do Scientists Pay to Be Scientists?” Management Science, 50 (June 2004): 835-53. 


\section{APPENDIX: Survey Instrument of Professors’ Preferences}

Please list the three aspects of your job that contribute most to your enjoyment of being a professor. One sentence for each is all that needs to be written.

1.

2.

3.

Gender: F

$\mathrm{M}$

Year Began University Teaching: 
Table 1. Usual Weekly Earnings of the Highly-Educated, CPS-MORG 2012-16*

Mean and

$\begin{array}{lllllll}\text { SE } & \text { Centile: } & 10 & 25 & 50 & 75 & \text { N }\end{array}$

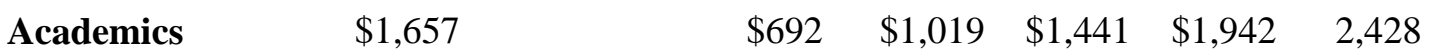

(20.75)

$\begin{array}{llllll}\text { Other Doctorates** } \quad \$ 2,023 & \$ 700 & \$ 1,057 & \$ 1,635 & \$ 2,500 & 22,880\end{array}$

In(Weekly Earnings), Parameter Estimate, Indicator Academic=1***

OLS Estimate Quantile Estimate

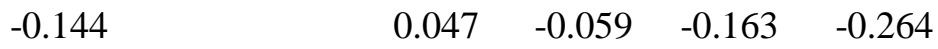

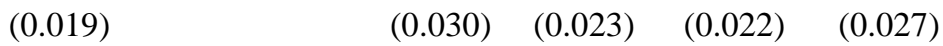

*Standard errors in parentheses below means and coefficients. All estimates use sampling weights.

**Has a Ph.D., M.D., J.D., Ed.D. or other doctorate.

***Includes quadratics in usual weekly hours and age, indicators for gender and marital status, number of own children under 18 in the household, and vectors of indicators of metropolitan status, survey year and state of residence. 
Table 2. Descriptive Statistics, Distribution of Hours, ATUS 2003-15*

Other

Academics Doctorates**

Recall usual weekly hours $\quad 46.27 \quad 45.54$

$(0.58) \quad(0.24)$

Week diary total $\quad 45.17 \quad 45.38$

(1.48) (0.56)

Weekly distribution of work:

Weekday diary total $\quad 41.20 \quad 41.71$

(1.33) (0.48)

Weekend diary total $\quad 5.45 \quad 3.93$

$(0.44) \quad(0.15)$

Daily distribution of work:

Percent with part of workday in:

Evening (7PM-10PM) $\quad 22.71 \quad 19.31$

(2.01) (0.76)

Night (10PM-6AM) $27.75 \quad 20.23$

(2.15) (0.77)

Seasonal distribution of work:

Weekly hours, June-August $\quad 38.91 \quad 43.16$

Weekly hours, Sept-May $\quad 47.43 \quad 46.09$

(1.72) (0.65)

$\begin{array}{lll}\mathrm{N}= & 481 & 3,688\end{array}$

* Standard errors in parentheses below means. All estimates use sampling weights.

**Has a Ph.D., J.D., M.D., Ed.D. or other doctorate. 
Table 3. Compensating Wage Differential Attributable to Weekly Work Smoothing in Academe (Percent Wage Shortfall)

$\begin{array}{cccccc} & & & \boldsymbol{\sigma} & & \\ \boldsymbol{\delta} & \mathbf{0 . 2 5} & \mathbf{0 . 5 0} & \mathbf{0 . 7 5} & \mathbf{1} & \mathbf{1 . 5 0} \\ \mathbf{0 . 2 5} & 4.7 & 2.6 & 1.6 & 1.0 & 0.4 \\ \mathbf{0 . 5 0} & 4.7 & 2.5 & 1.3 & 0.6 & 0.2 \\ \mathbf{0 . 7 5} & 4.7 & 2.4 & 0.8 & 0.3 & 0.1\end{array}$


Table 4. Determinants of the Probability of Listing a Job Characteristic in a Survey of Academic Economists, Probit Derivatives (N=289)*

\section{Characteristic:}

$\begin{array}{lcccccc}\text { Ind. Var.: } & \text { Research } & \text { Teaching } & \text { Interactions } & \text { Schedule } & \text { All other } & \text { Impact } \\ \text { Male } & 0.007 & 0.115 & -0.096 & -0.043 & 0.007 & 0.017 \\ & (0.043) & (0.062) & (0.068) & (0.066) & (0.056) & (0.044) \\ \text { North } & & & & & & \\ \text { American } & -0.011 & 0.011 & 0.047 & 0.108 & -0.098 & -0.085 \\ & (0.040) & (0.054) & (0.062) & (0.060) & (0.049) & (0.040) \\ & & & & & & \\ \text { Experience/10 } & 0.017 & 0.022 & 0.006 & -0.047 & -0.004 & 0.01 \\ & (0.016) & (0.022) & (0.024) & (0.023) & (0.020) & (0.016) \\ & & & & & & \\ \text { Pseudo-R }{ }^{2} & 0.007 & 0.016 & 0.007 & 0.018 & 0.014 & 0.019\end{array}$

*Standard errors in parentheses below parameter estimates. 


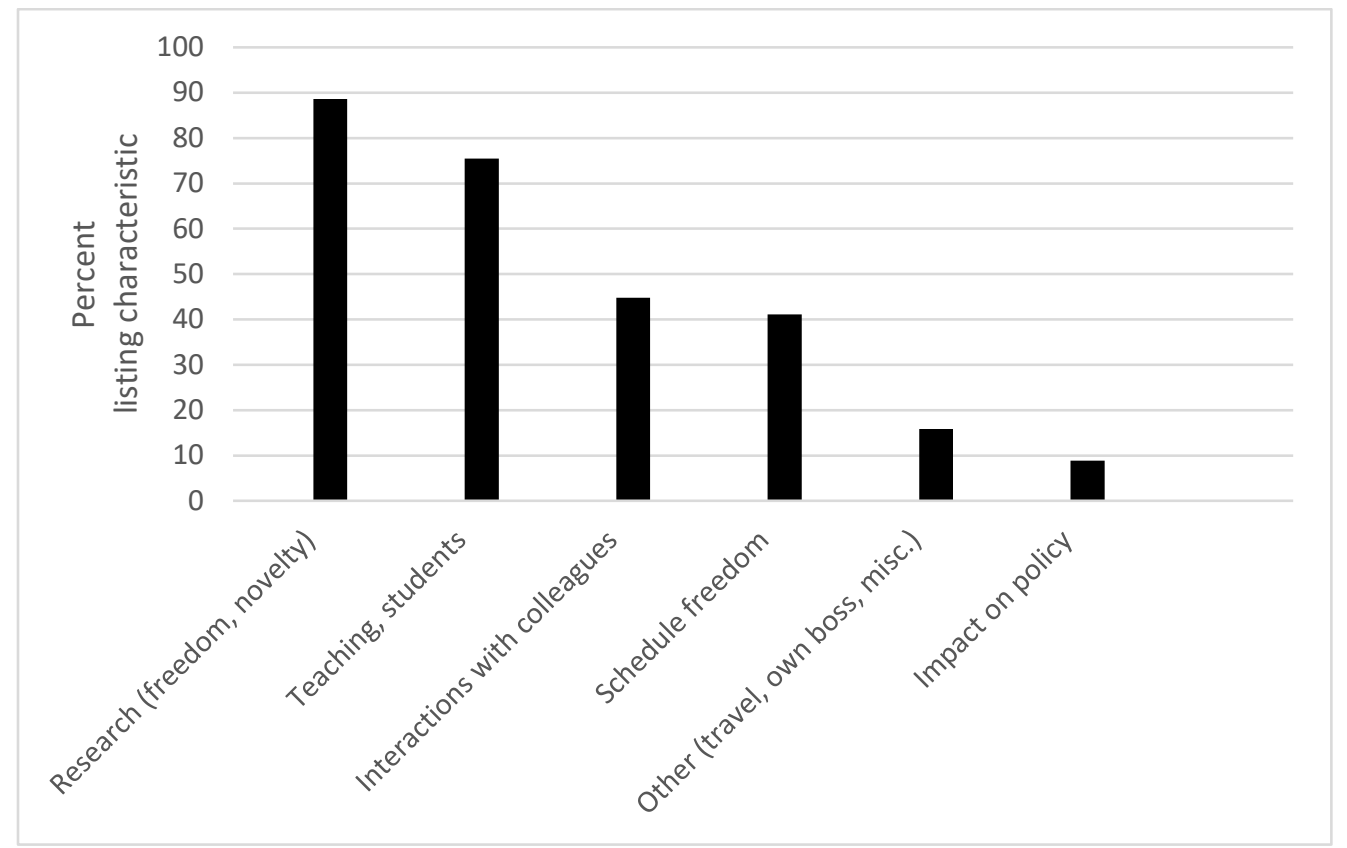

Figure 1. Predicted Percentage of Respondents Indicating the Characteristic Is a Top-Three Attraction ( $\mathbf{N}=\mathbf{2 8 9}$ ) 